\title{
Primeras poesías de Ramon Xirau
} José Ramón López García

\section{Citer ce document / Cite this document :}

López García José Ramón. Primeras poesías de Ramon Xirau. In: Exils et migrations ibériques au XXe siècle, n8, 2000. 60 ans d'exil républicain : des poètes espagnols entre mémoire et oubli. Anthologie. pp. 253-274;

doi : https://doi.org/10.3406/emixx.2000.1056

https://www.persee.fr/doc/emixx_1245-2300_2000_num_2_8_1056

Fichier pdf généré le 28/08/2018 


\section{Primeras poesías de Ramon Xirau}

\section{Presentación de José Ramón López García*}

La obra de Ramon Xirau cuenta ya hoy en día con aproximaciones críticas que han detectado con exactitud buena parte de sus inquietudes estéticas y filosóficas ${ }^{1}$. Sin embargo, su etapa inicial de formación y sus primeros años de producción intelectual y poética son territorios aún poco explorados en los que actúan las principales líneas de fuerza trazadas en el ambiente cultural mexicano y en los círculos específicos del exilio republicano español en México, esferas en más de un caso ampliamente interrelacionadas. Así, no han de olvidarse las influencias del debate existencialista -en pleno auge en los círculos universitarios mexicanos y en el que participan profesores como José Gaos- que se manifiestan en los primeros textos de la generacional revista Presencia, donde Xirau colabora destacadamente y elabora sus primeras críticas al existencialismo de Sartre desde una posición cristiana sustentada en la axiología, el bergsonismo y el personalismo heredados, sobre todo, de su padre, Joaquim Xirau ${ }^{2}$.

Los poemarios 10 poemes [10 poemas], L'espill soterrat [El espejo soterrado] y Les platges [Las playas] comprenden la obra poética escrita por Xirau entre 1950 y 1972, pero su actividad pública como poeta se inició en la revista Lletres, acompañado por Manuel Duran, en el año $1945^{3}$. Ni su tono ni su contenido escapan de la nota común de gran parte de la poesía exiliada de los años cuarenta, pero la tópica nostalgia de la patria del

\footnotetext{
* Universitat Autònoma de Barcelona.

${ }^{1}$ Las más importantes son las de Manuel Duran, Arthur Terry, y Eduardo Mateo Gambarte. Cf. bibliografía.

${ }^{2}$ Véanse los testimonios aportados por Xirau en Memorial de Mascarones y otros ensayos, México D. F., El Colegio Nacional, 1995.

3 “Dos poemes", Letres, México D. F., 7, octubre 1945, p. 12. Poemas, junto a otros que se reproducen a continuación, no recogidos en Poesia completa (1950-1994).
} 
desterrado que ansía el retorno, en su caso al espacio recurrente del Mediterráneo, se supera pronto mediante una integración mítica de este paisaje de la mediterraneidad infantil, construcción paradisíaca asimilada a un ámbito de percepción espiritual ${ }^{4}$.

Si tuviéramos que destacar en estos años un modelo sin duda sería el de Joan Maragall y su Elogi de la paraula que nos explican muchos aspectos de Xirau: la tendencia a la designación directa de la realidad a través de imágenes; que esta experiencia espiritual de la contemplación del paisaje remita a los parajes de su infancia; y que ello suponga la recuperación, recreada poéticamente, de ese mismo estado del espíritu infantil definido en la contemplación serena del mundo'. Se inicia así el camino hacia la asociación, en sus ensayos de madurez, de la poesía con el conocimiento y su identificación con lo divino, pues ya ahora su poética se articula alrededor de la esencialidad del poema, la simplicidad expresiva y el uso de imágenes como explicación del origen sagrado de la palabra poética $y$, de paso, de la realidad que designa. Por eso su poesía difícilmente será expresión de una realidad interior o exterior conflictiva porque aspira al reflejo de la armonía que las contradicciones aparentes ocultan ${ }^{6}$.

La simple descripción paisajística se ve de esta forma cargada de significados superpuestos porque "todo paisaje es paisaje del alma; el sereno reposo de un amanecer luminoso esponja el espíritu; y el espíritu deviene paisaje, paisaje franciscano del alma ${ }^{7, "}$. Estamos ante la articulación de la visión analógica -crucial en la cosmovisión romántica de la realidad y que tan bien explica Octavio Paz, otro modelo clave en su obra, en Los hijos del limo- manifestada en poemas tempranos como "Tres nocturns" [Tres

\footnotetext{
${ }^{4}$ Tema que perdura hasta hoy en Indrets del temps [Lugares del tiempo].

5 Véanse "Imatges i amors" [Imágenes y amores], La Nostra Revista, México D. F., I, 8, 15 de agosto 1946, pp. 292-293 y "Elogi de la Paraula" [Elogio de la palabra], Orféó Català, México D. F., I, 2, mayo 1962, p. 5, donde defiende esta lectura ejemplificada en Maragall, Ausiàs March y Ramon Llull.

${ }^{6}$ Bastaría confrontar las ideas de estos ensayos con la escritura poética de dos composiciones de 1945 -que, no casualmente, se agrupan bajo el título de "Dos poemes del mar" (La Nostra Revista, México D. F., I, 2, 15 de febrero 1946, p. 2)-para ver cómo, a la vez que se remite al modelo lírico de Maragall (es evidente el diálogo con sus poemas de Vistes al mar), se establece una continuidad con la expresión directa del paisaje mediterráneo que ha propuesto como clave de lectura de la tradición literaria catalana.
}

7 "Imatges i amors", art. cit, p. 292. Todas las traducciones del catalán son mías. 
nocturnos] u "Orígens" [Orígenes] $]^{8}$. Maragall también facilita una asimilación en sus propuestas de la ontología amorosa propugnada por Joaquim Xirau". En este sentido, la lectura de "Definicio" [Definición] ${ }^{10}$, se ajusta a lo que declara en 1946 cuando habla de la poesía de Ausiàs March y Ramon Llull como dos vertientes de la experiencia amorosa, pues el amor es origen y conclusión, visión contemplativa y armónica del mundo: "El mundo, creado por amor, es todo amor", nos dice en aquella ocasión, "todo es amor en todo", nos comunica ahora al cierre de este poema clave ${ }^{11}$.

Otras composiciones de estos años como "Somni" [Sueño] ${ }^{12}$, permiten establecer una fructífera comparación con lo teorizado en ensayos, aún inmaduros, como Duración y existencia ${ }^{13}$, donde, a partir sobre todo de Bergson, se establece una serie de relaciones entre fe y memoria, memoria y duración, duración y percepción que hacen comprensibles las intenciones de otros poemas. En "Llum en la vall" [Luz en el valle] hallamos la traslación poética de la tesis de que toda ausencia no nos remite a ninguna demostración de la nada sino, al contrario, es prueba de una presencia, algo adecuado al mencionado contexto polémico del debate existencialista ${ }^{14}$. Bergson, a quien relaciona con Maragall en otros ensayos de estos años ${ }^{15}$, es

\footnotetext{
8 "Tres nocturns", Presencia, México D. F., 3, enero-febrero 1949, pp. 10-11 y "Orígens (Dos fragments)", Pont Blau, México D. F., [2], octubre 1952, p. 16. Reproducido con el título "De quina matèria ets feta?" en L'espill soterrat, s. p., y, con la supresión de los últimos once versos, en Poesia Completa, p. 18.
}

${ }^{9}$ Véase Joaquim Xirau, Amor y mundo y otros escritos, recogido en sus Obras completas. 1: Escritos fundamentales, edición de Ramon Xirau, Rubí, Anthropos / Madrid, Fundación Caja Madrid, 1998.

${ }^{10}$ Poema que se integra sucesivamente en sus tres primeros libros. Primero como poema pórtico de 10 poemes, p. 7; como último poema, en este caso titulado "Esquirla del teixit...", en L'espill soterrat, s. p.; nuevamente como "Definicio" se publica en La Nostra Revista, México D. F., VII, 65, 1 de enero 1953, p. 12; y con el título de "Les platges delirants" pasa a integrarse, en versión reducida y dedicado a Jorge Guillén, en la primera sección, "Platges de la presència", de Les platges (en Poesia completa, p. 52).

11 "Imatges i amors", art. cit., p. 293.

12 “Somni” [Sueño], Presencia, México D. F., 2, septiembre-octubre 1948, pp. 20-21.

${ }^{13}$ México D. F., Instituto Francés de América Latina (IFAL), Terres latines, 1947.

14 "Llum en la vall" [Luz en el valle], Presencia, México D. F., 1, julio-agosto 1948, p. 11.

15 Véanse "La expresión de lo concreto", Cuadernos americanos. La revista del Nuevo Mundo, México D. F., VII, XL, 4, julio-agosto 1948, pp. 120-135 y "Notas sobre la visión en 
crucial para entender por qué el discurso de la modernidad se ha centrado, en parte de sus manifestaciones, alrededor de los conceptos recogidos por Xirau: superioridad de la percepción poética, traslación de esta percepción mediante la imagen, y lectura de ésta como manifestación de la intuición de la duración que se constituye en la auténtica realidad ${ }^{16}$.

El sentido que el exilio tiene en estos primeros poemas de Xirau es, con todo ello, más amplio de lo que a veces se ha considerado. No es sólo una contingencia personal, es reflejo de una circunstancia superior del ser humano, un correlato del paraíso perdido que puede recrear en este paisaje de su infancia doblemente perdido, por el paso del tiempo y por culpa del exilio, y doblemente recuperado, como memoria personal y como religación sagrada $^{17}$. Al fondo late una comprensión del paraíso mediterráneo como una posibilidad malograda de esa unidad que en diferentes ámbitos busca e invoca Xirau ${ }^{18}$. Construir este mundo a través de las imágenes utilizadas en sus poemas es la operación que recoge todos los procesos: unidad de la memoria y del espacio, personal y colectivo, que permite integrar desde el pensamiento político y filosofico hasta la tradición cultural y sus creencias religiosas.

Xirau perfila en estos años cuarenta una relación entre vida y poesía en la que, analizando las opciones de Juan Ramón, Alberti o Prados, selecciona

la poesía”, Presencia, México D. F., 5-6, julio-agosto 1949, pp. 85-91.

${ }^{16}$ Véase la excelente crítica realizada a estos puntos por Carlos Blanco Aguinaga en Sobre el modernismo, desde la periferia, Granada, Comares, 1998, pp. 38-42.

17 Estamos así también ante un procedimiento poético: "De hecho, las imágenes que se encuentran en mis poemas, buenos, regulares o malos, recuerdan aquellas costas bravas transfiguradas por la memoria y alteradas por el recuerdo", "De Filosofia i Poesia", en Doctor Honoris Causa. Eduard Nicol, Ramon Xirau, Barcelona, Universitat Autònoma de Barcelona, 1984 , p. 40.

18 Víctor Castells, "Catalans d'Amèrica. Enquesta. Ramon Xirau”, Serra d'Or, Barcelona, XIV, 149, febrero 1972, p. 32: “Cuándo es “ayer”? Antes que nada, mi "ayer”, recuerdos maravillosos: Llançà, Cadaqués, el Port de la Selva -"el puente de la mar azulada"-, domingos góticos en Barcelona. Navegaciones por nuestros mares, aún poco turísticos. Otro ayer: pienso que Catalunya pertenece al arco mediterráneo: Provença, Oc, València, Balears. Creo que este mundo, que prometía unidad no solamente cultural, sino también política, se desmiembra en el momento de la cruzada albigense. Tan nuestro es Arnau Daniel como Ausiàs March". 
al Juan Ramón de Espacio por la experiencia más positiva que provoca en él el exilio donde la melancolía se suma a una contemplación integradora: "el recuerdo de su tierra perdida no le es dolor, mas se le torna contemplación, visión clara, clamada, de la vida. Ante nosotros, a través del recuerdo, se abre, en su totalidad, una concepción del mundo, a que el poeta se siente inclinado. [...] No hay desesperación en el destierro de Juan Ramón. Hay, sí, en su obra, una quieta y despaciosa afirmación del ser del hombre, de su vinculación a los hombres, de su vinculación a todas las tierras de la tierra. [...] Y hasta parece que su melancolía ha desembocado en esta su luminosísima contemplación. Juan Ramón sigue en su tierra, porque lleva su tierra, la tierra que todos los hombres llevan en su existencia, en lo más hondo de su propio ser, y esta tierra real y soñada, esta tierra "amarilla" de sus poesías se funde en su vida de poeta, se funde en su obra, en una y la misma realidad ${ }^{19}$ ". La posición que adopta Xirau ante el exilio es muy parecida en la asimilación afirmativa del desarraigo y la integración del sentimiento de pérdida del paraíso. Por eso se ha identificado con el problemático neologismo creado por José Gaos para definir una de las posibles vivencias del exilio, "transterrado", porque para él "el mero recuerdo melancólico conduce a poco; el recuerdo robusto es aquel que se alía a un fuerte sentido de la presencia en el mundo real", un dato más a tener en cuenta cuandó se valora la intencionalidad de los recuerdos infantiles asociados con el paisaje mediterráneo que aparecen en muchas de sus composiciones ${ }^{20}$.

De todo ello dan buena cuenta estos primeros poemas de Ramon Xirau que me ha parecido útil recopilar en esta ocasión como muestra embrionaria del posterior desarrollo de una interesantísima poética de madurez ${ }^{21}$.

\footnotetext{
19 "Poesía de España en América", Presencia, México D. F., 5-6 (enero-febrero 1949), p. 28. Definición que se corresponde a la hecha por Claudio Guillén en El sol de los desterrados: Literatura y Exilio, Barcelona, Sirmio / Quaderns Crema, 1995, pp. 11-15 y 165-171.

${ }^{20}$ Ramon Xirau, "España vista desde el exilio en México, durante más de 25 años", Caravelle, Tolosa, 50, 1988, p. 83.

${ }^{21}$ Únicamente he recopilado aquellos poemas no recogidos en Poesia completa, así como aquéllos que en su primera publicación aparecieron con variantes que he considerado interesante reproducir. La traducción que propongo de los poemas es básicamente instrumental.
} 


\section{BIBLIOGRAFIA}

Obra poética de Ramon Xirau publicada en libros:

10 Poemes, México D. F., edición particular, 1951.

L'espill soterrat, México D. F., "Pròleg" de Agustí Bartra, Los Presentes-Lletres, 1955.

Les platges, Barcelona, Edicions 62 (Els Llibres de l'Escorpí. Poesia, 23), 1974.

Graons, prólogo de Octavio Paz, Barcelona, Edicions 62 (Els Llibres de l'Escorpí. Poesia, 51), 1979.

Dit i descrit, Barcelona, Edicions 62 (Els Llibres de l'Escorpí. Poesia, 81), 1983.

Ocells, Barcelona, Edicions 62 (Els Llibres de l'Escorpí. Poesia, 138), 1991.

Poesia completa (1950-1994), edición de Joan M. Pujals, Barcelona, Columna, 1995.

Indrets del temps, Barcelona, Edicions 62 (Els Llibres de l'Escorpí. Poesia, 189), 1999.

\section{Estudios sobre Ramon Xirau:}

AlCoBero, Ramon, "Ramon Xirau, Graons, Dit i descrit", Enrahonar, Quaderns de Filosofia, Departament de Filosofía, UAB, 10, 1984, pp. 202-205.

DuRAN, Manuel, "Ramón Xirau: una poesía fiel", Plural, México D. F., 37, octubre 1974, pp. 69-70.

DURAN, Manuel, "Ramon Xirau: from poetry to metaphysics", Catalan Review, Yale University, vol. 1, 2, diciembre 1986, pp. 85-99.

GonZÁlez, Juliana (ed.), Presencia de Ramón Xirau, México D. F., UNAM (Textos de Humanidades), 1986.

MATEO GANBARTE, Eduardo, "Ramón Xirau: el Mediterráneo exiliado en México", Exils et migrations ibériques au XXe siècle, Aznar/Dennis/Sicot (coords.), CERIC, Universite de Paris 7, 6, 1999, pp. 185-206. 
PAZ, Octavio, "Islas y puentes" [1974], Octavio Paz y Luis Mario Schneider (eds.), México en la obra de Octavio Paz. Generaciones y semblanzas. Escritores y letras de México, México D. F., FCE, 1987, pp. 508-513.

SANChez RoBayna, Andrés, "Graons", Vuelta, México D. F., 42, mayo 1985, pp. 36-37.

TERRY, Arthur, "Pensament i cant en la poesia de Ramon Xirau" i "Ramon Xirau: dir i descriure", Quatre poetes catalans: Ferrater, Brossa, Gimferrer, Xirau, Barcelona, Edicions 62, 1991, pp. 175-219.

\section{$\infty$ \\ DOS POEMES \\ OH, MIREU!}

Oh, mireu!

Les mars del món s'han recobert d'aurores, ja ens hem mirat de fit a fit, oh temps! Ja ens hem mirat en els miralls de l'alba $i$ en la rogenca cabellera estesa dels arbres destrenats a tots els vents.

Sota la verda soca, sota la negra nit d'estels, enmig dels pins, veure't de nou, oh terra de memories!, veure't de nou i amar-te amor endins.

Com una llesca d'or, reneix en el matí la clara terra i entra en la nit amarada d'amor. Parpellejant d'amor tots els estels em miren. Terra d'amor, detura el temps, amor! 
Detura el temps perquè la vida visqui en aquest món d'escumejants matins, perquè visqui la vida en tes contrades, perquè en morir m'enterrin sota els pins.

\section{¡OH, MIRAD!}

¡Oh, mirad!

Las mares del mundo se han recubierto de auroras, ya nos hemos mirado fijamente, joh tiempo! ya nos hemos mirado en los espejos del alba $y$ en la rojiza cabellera extendida de los árboles destrenzados a todos los vientos. Bajo el verde tronco, bajo la negra noche estrellada, entre los pinos, verte de nuevo, joh tierra de memorias! Verte de nuevo y amarte amor adentro.

Como una rodaja dorada, renace en la mañana la clara tierra y entra en la noche de amor empapada. Parpadeando de amor todas las estrellas me miran. ¡Tierra de amor, detén el tiempo, amor! Detén el tiempo para que la vida viva en este mundo de espumosos amaneceres, para que viva la vida en tus comarcas, para que al morir me entierren en tus pinares

NO PLORIS, DONZELLA...

No ploris, donzella, les hores passades, no ploris, amiga, quan passa el nou jorn, la neu que es fonia s'ha fet aigua clara, l'amor que es perdia s'ha fet nou amor. 
La blanca estelada d'eterna mirada, de blava, pregona, paraula del vent, la llisa llacuna de llum amarada, no passen, oh temps!

La lenta riuada de l'alba serena, la fosca calmosa que cau sobre el mar, la verda boscúria, l'amor i la vida, no passen, atzar!

(Lletres, Mèxic D. F., 7, octubre 1945)

NO LLORES DONCELLA...

No llores, doncella, las horas pasadas, no llores, amiga, el paso de un nuevo sol, la nieve que se fundía se ha hecho agua clara, el amor que se perdía se ha hecho nuevo amor.

Las blancas estrellas de eterna mirada, de azulada, profunda, palabra del viento, la lisa laguna de luz empapada, No pasan, joh tiempo!

La lenta riada del alba serena, la calma oscura que cae sobre el mar, el verde follaje, el amor y la vida, no pasan, jazar! 
DOS POEMES DEL MAR

Fred.

Frec a frec del pal de la barca, l'estel

asseca, en el moll,

la xarxa.

Fred.

El pal segueix l'estel

i el mar

s'adorm en l'oblit morat.

Cases negres.

Fum.

Poble; ciutat;

llum.

No hi ha gotes en l'aire, sinó la blanca llum.

Plou.

Magnòlies odorants, ensomnis del matí, veles al mar de l'alba.

Clavat en roc, el pi.

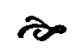

La mar del cel degota sobre el mar.

Blaves estrelles pul·lulen sobre el mar.

Vives estrelles remouen el blau mar.

De mar a cel, de cel a mar, ve l'alba

amb un teixit de lleus ruixims
DOS POEMAS DEL MAR

Frío.

Casi tocando el palo de la barca, la estrella

seca, en el muelle,

la malla.

Frío.

El palo sigue a la estrella y el mar

se duerme en el olvido morado.

Casas negras.

Humo.

Pueblo; ciudad;

luz.

No hay gotas en el aire, sino la blanca luz.

Llueve.

Olorosas magnolias, ensueños de la madrugada, velas al mar del alba.

Clavado en roca, el pino.<smiles></smiles>

La mar del cielo gotea sobre el mar. Azules estrellas pululan sobre el mar.

Vivas estrellas remueven el azul mar.

De mar a cielo, de cielo a mar, viene el alba con un tejido de leves lloviznas 
gelats.

De mar a cel, de cel a mar, la fosca, amb una xarxa blava, pesca els estels del mar.

Un somni d'algues lentes ondulava

del mar cap al cel, del cel cap al mar. heladas.

De mar a cielo, de cielo a mar, la oscuridad, con una red azulada, pesca las estrellas del mar.

Un sueño de algas lentas ondulaba del mar al cielo, del cielo al mar.

(La Nostra Revista, Mèxic D. F., I, 2, 15 de febrero 1946)

\section{LLUM EN LA VALL}

¡Senyor! Llum en la vall.

Lent, amorós, l'alè del vent besa la plana.

Jo sóc tot sol aquí, la música s'atansa i com l'esquirla que m'arranca -llumla tremolosa branca, en caure seca, nítida al ponent tu em mires erta i el tacte buit se'm glaça!

¡Senyor! Llum en la vall i tremolosa l'ombra de la branca.

¡Oh! morta, terra morta de viure, llaç sense esperança.

Llisca la flor vermella en l'herba

\section{LUZ EN EL VALLE}

¡Señor! Luz en el valle. Lento, amoroso, el aliento del viento besa la plana.

Yo estoy solo aquí, la música se acerca y como la esquirla que me arranca-luzla temblorosa rama, al caer seca, nítida al poniente tú me miras yerta iy el tacto vacio se me hiela!

¡Señor! Luz en el valle. y temblorosa la sombra de la rama.

¡Oh! muerta, tierra muerta de vivir, lazo sin esperanza.

Resbala la flor roja en la hierba 
mansa.

¿Per què, Senyör, la llum sobre la [plana? mansa.

¿Por qué, Señor, la luz sobre la

Iplana?

(Presencia, México D. F., 1, julio-agosto 1948)

\section{SOMNI}

Aquelles fulles blanques en la penombra tendra! el temps ens regalima avall dels dits i els arbres arrelats, de terra i cel, remouen llurs caps

llurs troncs emperesits.

[blanquíssims,

La mar es repeteix

-tan sordament-

esquena endins,

al plec de l'ombra obscura i blava

del bategar latent del cos dormit.

Aquestes flors de juny,

clares de fred i denses d'aigües fredes,

se'ns filtren ulls endins, devers els somnis blaus

d'un blau puríssim, llacs endins, Senyor, dels ulls, dels llacs, dels cels, endins, com un vol lent

d'alè amorós i pàl·lid.

Aquelles fulles blanques!

Senyor, les fulles blanques de la nit.

... aquesta nit tan negra com l'escuma

del nostre temps, del nostre mar, del nostre amor,

del nostre temps, Senyor, la nit tan fina

tan fred el meu record i empal-lidit.

Aquests estels em miren des de l'aigua, em miren des de l'aigua els Teus estels, aquesta nit tan negra, el brill i l'ombra, el parpelleig del cel, el brill del cel, 
Senyor dels cercles lents de l'aigua somniosa, em miren els estels, em miren els estels, els Teus estels...

se'ns va filtrant la nit endins, el somni és lent, se'm va filtrant la teva nit, les fulles van caient, pluja deserta d'oblits i de memòries al fons de mi, al fons de tu, al fons dels pàl-lids deserts de la nit blava, al fons dels deserts del cel, al fons dels arbres sense fons.

Les distàncies, Senyor, se'm fan més llargues, al fons, Senyor, endins, al fons...

(Presencia, México D. F., 2, septiembre-octubre 1948)

\section{SUEÑO}

Aquellas hojas blancas en la penumbra tierna el tiempo nos chorrea bajo los dedos y los árboles arraigados, de tierra y cielo, remueven sus [copas blanquísimas, sus troncos perezosos.

La mar se repite

-tan sordamente-

espalda adentro,

en el pliegue de la sombra oscura y azul

del palpitar latente del dormido cuerpo.

Estas flores de junio, claras de frio y densas de aguas frías, se nos filtran ojos adentro, hacia los sueños azules de un azul purísimo, lagos interiores, Señor, de los ojos, de los lagos, de los cielos, adentro, como un vuelo lento de aliento amoroso y pálido.

¡Aquellas hojas blancas!

Señor, las hojas blancas de la noche. 
... esta noche tan negra como la espuma de nuestro tiempo, de nuestro mar, de nuestro amor, de nuestro tiempo, Señor, la noche tan fina, tan frío mi recuerdo y empalidecido. Estas estrellas me miran desde el agua, me miran desde el agua Tus estrellas, esta noche tan negra, el brillo y la sombra, el parpadeo del cielo, el brillo del cielo, Señor de los círculos lentos del agua soñadora me miran las estrellas, me miran las estrellas, Tus [estrellas...

se nos va filtrando la noche adentro, el sueño es lento, se me va filtrando tu noche, las hojas van cayendo, lluvia desierta de olvidos y de [memorias al fondo de mí, al fondo tuyo, al fondo de los pálidos desiertos de la noche azul, al fondo de los desiertos del cielo, al fondo de los árboles sin fondo.

Las distancias, Señor, se me hacen más largas, al fondo, Señor, adentro, al fondo...

\section{TRES NOCTURNS}

La terra dorm. Tu no has vingut. Espera.

La terra neix en cada bri de nit.

Amor, l'ona del temps romp en les roques.

Amor somnia lent el meu desig; els pins gelada plouen de rosades.

Amor que no has vingut aquesta nit.

Cada fulla més verda, molsa d'ombra, goteja lliris blancs.

Tu no has vingut. 
Cada mirada d'aigua de les fulles omple el meu cor de fosca i de neguit.

Tu no has vingut, amor, de matinada, que no vingueres, ombra de la nit.

Tu no has vingut. Ocells de plomes blanques

obren llurs calces blancs a l'infinit.

Vermelles flors molsoses d'herbes fines, blavoses flors del cel, estels del pit. Veniu amb mi, veniu, a frec de l'alba amors que no vinguéreu en la nit.

\section{II}

L'aigua era un tel de transparència blava l'aigua em mirava en els teus ulls de nit. Molla de llum la terra s'adormia.

Detura't, vaig pensar... Era l'oblit.

La nit es traslluiia amunt del cel, en els estels, estels de llum més blava. L'aigua em mirava en els teus ulls de nit. L'aigua era un tel de somnolència clara.

El negre blau del cel, mirava, endins, i l'ànima d'amor es transformava, en blaus estels, flors blaves, ocells blaus, en el silenci blau de l'aigua blava.

Res més. Silenci. Vaig pensar, detura't. Res més. El somni blau del meu oblit. Silenci, vaig somniar. D'onades blaves, les ombres s'emboiraven en la nit. 
Caminava en la nit d'ombra més alta. L'aigua del riu descabdellava estels.

Les fulles tendres, l'herba arrebossada.

Vaig aixecar els ulls endins del cel.

La terra molla, panteixava, lenta.

Plovia lentament, plovien lentament estels de l'alba del fons del cel a l'aigua, del fons de l'aigua al cel.

(Presencia, México D. F., 3, enero-febrero 1949)

\section{TRES NOCTURNOS}

\section{$\boldsymbol{I}$}

La tierra duerme. Tú no has venido. Espera.

La tierra nace en cada brizna de noche.

Amor, la ola del tiempo rompe en las rocas.

Amor sueña lento mi deseo;

los helados pinos llueven rocio.

Amor que no has venido esta noche.

Cada hoja más verde, musgo de la sombra, gotea lirios blancos.

Tú no has venido.

Cada mirada de agua de las hojas

llena mi corazón de oscuridad y desasosiego.

Tú no has venido, amor, de madrugada, que no vinieras, sombra de la noche.

Tú no has venido. Pájaros de plumas blancas abren al infinito sus blancos listones. 
Rojas flores musgosas de hierbas finas, estrellas del pecho, del cielo azuladas flores.

Venid conmigo, venid, cercana el alba, amores que no vinisteis en la noche.

\section{II}

El agua era una tela de transparencia azul el agua me miraba en tus ojos sombrios. Mojada de luz la tierra se adormecía. Deténte, pensé... Era el olvido.

La noche se traslucía más allá del cielo en las estrellas, estrellas de luz más azulada. El agua me miraba en tus ojos de noche. El agua era una tela de somnolencia clara.

El negro azul del cielo, miraba, adentro, y el alma de amor se transformaba, en azules estrellas, flores azules, pájaros azules, en el silencio azul del agua azulada.

Nada más. Silencio. Pensé, deténte. Nada más. El sueño azul de mi olvido. Silencio, soñé. De olas azules, las sombras se embrumaban en la noche.

\section{III}

Caminaba en la noche de más alta sombra.

El agua del río estrellas desovillaba.

La hierba tapada, las tiernas hojas.

Al interior del cielo alcé la mirada. 
La tierra mojada, jadeaba, lenta.

Llovía muy lento

llovían lentamente estrellas del alba

del fondo del cielo al agua,

del fondo del agua al cielo.

\section{AMOR-AGOST}

Un arbre foll d'ocells, una mirada i un rierol que llisca com un ram i una llum de setembre encastellada enmig de les agulles del rocam.

Tot és absurd. Absurd. La tramuntana aixeca més faldilles que perfils, rebolca enamorats en la tartana, i així embolica que fa fort els fils.

La noia pel carrer, tota encisada, es posa com un gra de cirerer $i$, ai que no ho sé ni ho sap, enamorada, ai que no ho sé ni ho sap què vol ben bé

Pel perfil de les branques, les parelles vestides de teixits de paper fi s'emporpren d'amor blau com les ovelles que poc a poc al mar van de matí.

$\mathrm{Ai}$, la noia que surt de la pedrissa! $\mathrm{Ai}$, la noia que surt del fonollar, agost, i la campana de la missa plateja com l'ocell, si fa no fa!

Tot és amor, agost, setembre o palla, tot és amor, irònic o gentil, $i$ anem a la muntanya i el vent talla branques de sol, com la tisora el fil. 


\section{AMOR-AGOSTO}

Un árbol loco de pájaros, una mirada y un riachuelo que como una rama corretea y una luz de septiembre encastillada en medio de las agujas de la roqueda.

Todo es absurdo. Absurdo. La tramontana más que perfiles levanta faldas revuelca enamorados en la tartana, y así las cosas aún más enmaraña.

La muchacha por la calle, encantada, se pone como una cereza y, jay que no lo sé ni lo sabe!, enamorada, iay que no lo sé ni lo sabe qué desea!

Por el perfil de las ramas, las parejas vestidas con tejidos de papel delicado se empurpurinan de amor azul como las ovejas que poco a poco al mar van muy temprano.

¡Ay, la muchacha que sale de la pedriza!, Ay, la muchacha que sale del hinojal, agosto, y la campana de la misa platea como el pájaro, ¡casi igual!

Todo es amor, agosto, septiembre o paja, todo es amor, con ironía o gentileza, y vamos a la montaña y el viento saja ramas de sol, como al hilo la tijera.

(La Nostra Revista, Mèxic D. F., V, 55-56, julio-agosto 1952) 


\section{ORÍGENS}

(Dos fragments)

"De quina matèria ets feta? Cap a tu totes les ombres vénen."

Mar blava, lliri blau, devers les ones els cérvols del matí per les muntanyes davallen tots glaçats. El teu secret. Res més que el teu secret.

On ets? Et cerca la meva mà ferida. Un lliri blanc, mar blanca, pura, esberla, llima, vaixell de sorra, castells d'aigua neta. Oh, lliri meu! Llunyanes, les boscúries planegen en el camp. No ho sé. Res més.

Secret ombrívol, llima de remolcs em cerca prop de tu. A les muntanyes, el mateix gel de sempre fa costums de vares blanques. Terra de llum. On ets?

Les mans et cerquen. Et palpen els meus ulls. Els meus sentits, els meus secrets, et cerquen, palpen, trien. El casc prop de la barca renova vells combats de peixos lleus. Una mirada. On ets? Equips de fauna poblen els meus records. Secretament encises... On ets, llaç, llima, arena? Unes mans pures davallen del cel blanc, lliri, de llum, i et fan desfici les mirades del meu record que et cerca en els penyals. Déu obre les esperances del temps en dos braços de cendra, i l'infant puja les escales de la boira cap a Ningú, cap a l'absència dels seus somnis, útils de llum.

Escala de costum, costum de somni. Viure com sempre, eternament, 
no sé si cendra o molsa o vida nova, nul fill d'Adam.

(Pont Blau, Mèxic D. F., 2, octubre 1952)

\section{ORIGEN}

(Dos fragmentos)

“De qué materia estás hecha? Hacia ti todas las sombras vienen."

Mar azul, lirio azul, a través de las ondas los ciervos de la mañana por las montañas descienden helados. Tu secreto.

Nada más que tu secreto. ¿Dónde estás? Te busca mi mano herida. Un lirio blanco, mar blanca, pura, esquirla, molusco, barco de arena, castillos de agua limpia. ¡Oh, lirio mio! Lejanos los bosques planean en el campo. No lo sé. Nada más. Secreto umbrio, molusco de remolques, me busca cerca tuyo. En las montañas el mismo hielo de siempre nos acostumbra a varas blancas. Tierra de luz. ¿Dónde estás? Las manos te buscan. Te palpan mis ojos. Mis sentidos, mis secretos, te buscan, palpan, escogen. El casco cercano a la barca renueva viejos combates de peces leves. Una mirada. ¿Dónde estás? Equipos de fauna pueblan mis recuerdos. Secretamente encantas... ¿Dónde estás lazo, molusco, arena? Unas manos puras descienden del cielo blanco, lirio, de luz, y te desasosiegan las miradas de mi recuerdo que te busca en los peñales. Dios abre las esperanzas del tiempo en dos brazos de ceniza, 
y el niño sube las escaleras de la niebla

hacia Nadie,

hacia la ausencia de sus sueños,

útiles de luz.

Escalera de costumbres, costumbre de sueño.

Vivir como siempre, eternamente, no sé si ceniza o musgo o vida nueva, nulo hijo de Adán.

\section{DEFINICIó}

Esquirla del teixit amfibi de les algues un ull de glaç oneja: peix-pedra a frec de molsa.

Niuada en el pedreig del fons de l'aigua viva, corculla de costum:

la roca llima rels.

Un peix-ocell desprèn

les ales de la fusta encesa de l'escorça: la mar el fa mirall.

L'ocell-esquirla en l'arbre (corall de neu ferit) beu líquids grans de fusta: encèn les fulles d'or.

Déu posa en els graons benignes de les coses petjades que son rels: tot és Amor en tot.
DEFINICIÓN

Esquirla del tejido anfibio de las algas un ojo de hielo ondula: pez-piedra casi musgo.

Nidada en la pedrea del fondo del agua viva, carcoma de costumbre: la roca lima raíces.

Un pez-pájaro desprende las alas de la madera encendida de la corteza: la mar le hace de espejo.

El pájaro-esquirla en el árbol (coral de nieve herida) bebe líquidos granos de madera: enciende las hojas de oro.

Dios pone en los escalones benignos de las cosas pisadas que son raíces: todo es Amor en todo.

(La Nostra Revista, México D. F., VII, 65, 1 de enero 1953) 